\title{
ИДЕНТИЧНОСТЬ ЛИЧНОСТИ КАК ПРОБЛЕМА СОВРЕМЕННОГО ОБЩЕСТВА
}

\section{В.С. Писчиков, М.М. Холин}

Среди разнообразных феноменов современной цивилизации, вызывающих тревогу и все более пристальное внимание исследователей, необходимо назвать и кризис идентичности. Как отмечает в связи с этим современный французский философ Марк Оже, «есть все основания описывать кризис современного мира как кризис идентичности» [6, с.140]. Деперсонализация и деиндивидуализация, вытеснение духовности псевдодуховностью, вестернизация в ходе глобализации национальньх культур, тотальная фальсификация используемых человеком предметов, - во всех этих и подобных им столь различных по своей природе явлениях есть одно общее свойство - потеря подлинности, идентичности.

В содержании кризиса идентичности современного общества как глобальном процессе обнаруживаются два аспекта, которые можно обозначить как социокультурный и антропологический. В первом случае речь идет о деформациях в природе социокультурных явлений и процессов - демократических политических институтов, многоликого мира ценностей, религиозной веры и разнообразных форм ее институциализации (особенно нетрадиционных), культурно-информационного пространства масс-медиа и др. Второй же из названных аспектов связан с деформациями в содержании важнейших характеристик и качеств самого человека как индивида, личности и индивидуальности во всех его ипостасях и проявлениях. Об этом аспекте проблемы и пойдет речь в данной статье.

Если попытаться выявить истоки проблемы человеческой идентичности в философии, то они обнаружатся прежде всего у С. Кьеркего-

Актуальні проблеми духовності: зб. наук. праць / Ред.: Я.В. Шрамко Вип. 10. - Кривий Ріг, 2009, 41-50 
ра и К. Маркса, а несколько позже - в философии жизни и у таких персоналистически ориентированных представителей русской философии начала XX века, как Н. Бердяев и Л.Шестов. Правда, можно найти и более давний философский «след» проблемы: в консервативной конфуцианской идее «чжэн мин»- «исправления имен» как необходимости с течением времени восстанавливать в неизменном виде первоначальный смысл жизненно важных понятий, так как «если имена неправильны, то слова не имеют под собой оснований. Если слова не имеют под собой оснований, то дела не могут осуществляться» [5, c. 161-162]. В современном же ее понимании проблема идентичности личности стала предметом осмысления относительно недавно, в середине - второй половине ХХ столетия в экзистенциализме, неомарксизме, прежде всего Франкфуртской школе, французском постструктурализме, в работах Эриксона и Левинаса.

Устоявшееся понимание личностной идентичности как тождественности человеческого индивида самому себе в процессе развития и самореализации, многообразных форм коммуникативных связей его с миром, на наш взгляд, в достаточной степени выражает ее суть. Как интегральное качество индивида его идентичность существует на нескольких уровнях и структурно может быть представлена как биологическая (телесная), психическая, духовная и социокультурная самотождественность.

Что касается телесной идентичности человеческого индивида, то на протяжении тысячелетий она не заключала в себе проблемности: с начала и до завершения своего жизненного пути он оставался биологически идентичным (за исключением естественных изменений, связанных с возрастом и болезнями). Однако успехи биологии и медицины в XXXXI столетиях могут существенно изменить ситуацию. Речь идет о получившей уже достаточно широкое распространение практике замены органов человеческого тела, пластических операциях, коррекции пола и других способах трансформации телесной идентичности индивида. Еще более радикальные и небезопасные изменения в этом направлении открывает возможная перспектива целенаправленного вмешательства в наследственность человека на генетическом уровне-генная инженерия, уже широко и весьма успешно используемая применительно к растениям и животным. В этом же ряду стоит и открывшаяся совсем недавно возможность клонирования человека.

Духовная, социокультурная, да и психическая самотождественность индивида проявляется прежде всего в его личностной идентичности. Само это понятие многоапектно, поэтому экспликация его со- 
держания выявляет ряд сущностных признаков идентичности - целостность, устойчивость, преемственность, индивидуальность, а также определенную степень автономности личности как необходимое условие и предпосылку идентичности.

Достижение и сохранение целостности личностной идентичности не происходит автоматически, а представляет собой сложный процесс, не лишенный определенньх трудностей, диспропорций и противоречий. Поэтому принципиально важную значимость в этом имеет осознанное, целенаправленное регулирование личностью хода и направленности процесса самоидентификации, следствием чего и может стать органическая целостность идентичности. Безусловно, это предполагает не только содержательную целостность каждого из структурных уровней идентичности индивида, но и гармоничность в их соотношении. Однако ведущая роль в интеграции личностной идентичности все же принадлежит духовному уровню ее, так как именно внутренняя взаимосогласованность и гармоничность духовного мира личности (духовных потребностей и интересов, чувств и эмоций, ценностей и мировоззренческих представлений) выступает в качестве основного фактора целостности ее идентичности как системы. Дезинтеграция духовного мира личности в качестве необходимого следствия влечет за собой и нарушение целостности биологического функционирования и психической жизни индивида, а также соцокультурных способов и форм его самореализации и самоутверждения.

Поскольку индивид живет и действует, непрестанно изменяясь в изменяющемся мире, то его самотождественность возможна лишь при условии устойчивости его сущностных качеств как личности и индивидуальности. Устойчивость же личностной идентичности во времени сохраняется лишь благодаря преемственности в ходе ее неизбежных трансформаций. В качестве основания устойчивости и преемственности идентичности и выступает ее целостность как скрепляющее, интегрирующее начало.

Самотождественность человеческого индивида как личности предполагает тождество не только его сущностных характеристик, но также и тех качеств, которые выражают его своеобразие, неповторимость. Поэтому идентичность личности имманентно включает в себя и ее индивидуальность. Обретение и сохранение индивидом своей идентичности, с одной стороны, и формирование и развитие его самобытности, с другой - это два взаимосвязанных и взаимообусловливающих друг друга аспекта одного и того же процесса.

Важнейшие качества идентичности (целостность, устойчивость, 
преемственность и индивидуальность) обусловливают определенную степень автономности индивида по отношению к другим индивидам, а также к тем формальным и неформальным объединениям, общностям и организациям, к которым он принадлежит. С другой стороны, наличие определенной степени автономности индивида является необходимой предпосылкой становления и сохранения его самоидентичности в процессе разнообразных внешних влияний социального характера.

Однако при этом принципиально важна мера индивидуальной автономности личности по отношению к ее микро- и макросреде. Чрезмерное дистанцирование от них оказывает негативное воздействие на становление и развитие личности во всех ее проявлениях, включая и идентичность. Процесс самоидентификации личности ошибочно рассматривать как всецело протекающий во внутреннем, духовном мире личности и независимый от всего внешнего в ее жизнедеятельности. В действительности он осуществляется в процессе многообразных форм деятельной активности личности - освоения ею культуры, самореализации и самоутверждения. Поэтому, как верно отмечает В.С. Барулин, «идентификация означает выстраивание своеобразного бесконечного количества внутренних линий, связывающих человека с макросоциальным миром, в котором он живет. Это множество нитей ... образуют своеобразную панораму внутреннего духовного самоощущения человека» $[1$, с. 356]. Процесс идентификации личности с этой стороны выступает как интериоризация ею социокультурных воздействий в ходе многообразных коммуникативных отношений, а тем самым и как результат взаимодействия индивидуально-личностного и социокультурного начал. В этом случае трудно не согласиться с Ю. Хабермасом, что «никакой человек не может распоряжаться своей идентичностью так, как если бы она была его собственностью. . Я Я не могу просто для себя самого удержать то я, которое в моем сознании предстает как данное мне, 一 оно не ,принадлежит“ мне» [10, с. 38,39].

Принимая социокультурную детерминированность процесса идентификации личности как непреложный факт, не следует упускать из вида две возможные, одинаково губительные для ее идентичности крайности - конформизм и эгоцентризм. Конформизм как жизненная ориентация и психологическая установка ведет к самоотождествлению индивида, его внутреннего «я» с целым, к которому он принадлежит социумом, нацией, социальной группой или институтом, общественной организацией, коллективом и т. д. При этом, по выражению признанного исследователя данной проблемы Э.Фромма, индивид-конформист «полностью подчиняется человеку, группе, институту или богу», а его 
«самоотождествление покоится на чувстве несомненной принадлежности к стаду» [9, с. 452]. Устранение необходимой дистанции между индивидом и общностью, в которую он входит, исключает объективную возможность формирования, сохранения и развития его индивидуальности и идентичности.

В противоположность конформизму эгоцентризм, напротив, возводит в абсолют независимость индивида, противопоставляя его миру. Тем самым существенно ограничивается, сужается единственный источник, из которого личность может черпать содержательный материал необходимый для формирования и развития своей идентичности. Эгоцентризм является мировоззренческой основой индивидуализма и эгоизма, в которых со всей определенностью и полнотой проявляется его негативное воздействие на развитие индивида как личности и индивидуальности. Одним из первых в свое время об этом со всей определенностью писал Н. Бердяев: «Эгоистическое и самолюбивое погружение в себя означает болезненную разорванность человека и мира... Индивидуализм есть опустошение индивидуальности, обеднение ее, умаление ее мирового содержания» $[3$, с. 255,376$]$.

Диалектическое понимание социокультурной обусловленности процесса самоидентификации в отличие от конформизма и эгоцентризма позволяет личности гармонизировать свое естественное стремление к самобытности и, следовательно, к сохранению определенной степени автономности в социуме, и столь же естественную потребность единения с ним и культурой как сферами общего. Наблюдая в конце XIX века противоположную тенденцию в западноевропейской культуре, великий испанский поэт и выдающийся мыслитель Мигель де Унамуно писал: «Великое безрассудство - хотеть лишить нас общего основания, единого теста, из которого слеплены различные формы, того, что делает нас похожими и связывает, того, благодаря чему мы становимся ближними... Сколько упорства в том, чтобы возвести на пьедестал неподлинное, отличающееся, гримасу, карикатуру!» $[8$, с. 116].

Исключительную роль в процессе идентификации личности играет духовность, ориентирующая индивида на универсальные абсолютные ценности. Первостепенную значимость среди них имеют моральные и мировоззренческие принципы и идеалы, определяющие систему координат, стратегию бытия личности, на основе которой она вырабатывает свои жизненные приоритеты и ценности. Таким способом духовность предостерегает и уберегает личность от крайностей эгоцентризма и нонконформизма. В то же время освоение духовных ценностей это не механический процесс их восприятия, а творческая ассимиля- 
ция, преломление их личностью через свою индивидуальность в ходе рефлексии. В результате этого общезначимые ценности приобретают характер индивидуально-личностных конструктов, которые несовместимы с конформистским восприятием и отношением к действительности.

Таким образом, есть все основания рассматривать духовность как необходимую, диалектическую по своей внутренней сути, форму самоидентификации личности ${ }^{1}$. Однако принципиально важно при этом, чтобы в процессе выбора личностью духовных ценностей не произошла подмена их псевдоценностями. Только подлинные духовные ценности (добро, любовь, истина, красота, справедливость, свобода и др.), имманентно сочетающие в себе индивидуально-личностное и социальное, конкретно-историческое и вечное, коллективно-групповое и общечеловеческое, идеальное и практически действенное, дают возможность индивиду рационально осмыслить и соотнести эти противоположные интенции в повседневных ситуациях, житейских ориентациях и целях. Лишь в этом случае идентичности личности могут быть органично присущи не только осознание своей самости и одновременно укорененности в бытии, но и согласие с критериями моральности.

Нынешнее состояние процесса идентификации личности в современном обществе, как уже упоминалось в статье, может быть обозначено как кризисное. Радикальные изменения негативного характера трансформировали природу идентичности, а также восприятие ее и отношение к ней как личности, так и общества.

Непосредственно кризис идентичности личности выражается в деформации всех ее сущностных признаков, в частности, таких неразрывно взаимосвязанных как целостность, устойчивость и преемственность: «,целостность“ и ,преемственность“ стали чувствами редко испытываемыми в наше время... Более того, их больше не желают испытывать, а если и хотят этого, то подобное желание, как правило, сопряжено со зловещими предположениями и страхами» [2, с. 186], констатирует известный британский социолог Зигмунт Бауман. Причина этого противоречащего природе идентичности явления в коренных изменениях социокультурной ситуации, в которой оказался современный человек. Речь идет о таких переменах, как многократно возросшая динамика социальных процессов; усиление существующих и возникновение новых форм социального отчуждения личности; утра-

${ }^{1}$ Подробнее об этом см. в нашей статье «Духовность как форма самоидентификации личности» // Актуальні проблеми духовності.-Зб. наукових праць. Вип. III. - Кривий Ріг, 2000. - С. 136-148. 
та связи индивида с традиционной системой норм и ценностей в контексте общекультурного кризиса традиционализма; доминирование в обществе потребительского образа жизни и связанных с ним ценностей и ориентаций.

Обретение личностью своей идентичности в новой социокультурной ситуации уже само по себе превращается в весьма непростую жизненную проблему. Однако не менее сложно для личности сохранить и развить в таких неблагоприятных объективных условиях свою идентичность как целостную, устойчивую систему психических качеств и установок, мировоззренческих и моральньг принципов, ценностных ориентаций и поведенческих стереотипов. Обладающая такими качествами идентичность стала для индивида в изменившихся социальных условиях не просто ненужной роскошью, но и негативным рудиментом, так как она предопределяет, программирует неадекватность его действий и поступков, лишая возможности динамично и гибко приспосабливаться в утилитарных целях к непрерывно изменяющимся обстоятельствам и тем самым обрекая его зачастую на жизненную неудачу. «Обретение четкой идентичности, раз и навсегда придающей всем и каждому „целостность“ и ,преемственность“, закрывает ряд возможностей либо заранее лишает прав на их использование» [2, с. 187].

Таким образом, традиционная («консервативная») идентичность не только обесценивает, но и дискредитирует себя в глазах индивида-потребителя-конформиста, воспринимаясь им в лучшем случае как нечто устаревшее и отжившее. Поскольку же без личностной идентичности человек как отдельный индивид в принципе существовать не может, то следствием этого становится ее трансформация, как бы «перевод» в иной содержательный и временной статус: целостность, устойчивость и преемственность как атрибуты идентичности заменяются фрагментарностью, эклектичностью и прерывностью в процессе ее изменений, а долговременность и постоянство-кратковременностью и ситуативностью. Индивид, обладающий такой трансформированной идентичностью уже не задается целью обрести себя, свое внутреннее «я», оставаться самим собой в калейдоскопе жизненных перемен и ситуаций, а без «ненужных» эмоций и болезненных переживаний «своевременно» заменяет свою идентичность другой, наиболее соответствующей изменившимся жизненным обстоятельствам. Так личностная идентичность из константной - идентичности «на всю жизнь»- превращается в величину переменную-ситуативную идентичность «на время». Как весьма удачно выразился в связи с этим К. Лэм, «идентичности, которых жаждут в наши дни, представляю- 
тся чем-то, что может надеваться и сниматься вроде костюма» (цит. по: [2, с. 187]).

Перерождение идентичности личности в процессе ее кризиса не могло не деформировать и такой ее атрибут как индивидуальность. Претерпевающее на протяжении жизни индивида многократные метаморфозы его внутреннее «я» несовместимо с развитой, охватывающей его личностные качества самобытностью. Неискоренимая тяга индивида к своеобразию, неповторимости остается, но все больше проявляется во второстепенном и внешнем: прическа, украшения, одежда, используемые вещи, поведенческие формы самовыражения - эти «последние остатки индивидуальности» (Э. Фромм) - становятся признанной и едва ли не основной формой манифестации индивидуальности личности. Поскольку же всевластная и всепроникающая мода уравнивает индивидов и в этом, то их стремление к оригинальности все больше находит свое выражение в крайних формах - экстравагантности и эпатажности. Вследствие переакцентировки в содержании индивидуальности с внутреннего, глубинного на внешнее и второстепенное, личностные качества индивида, теряя своеобразие, все более становятся усредненными и безликими - конформистскими.

Автономность личности как предпосылка и необходимое условие ее идентичности в кризисной ситуации также претерпевает негативные изменения. Гипердинамизм и стихийность социальных перемен, а также усиление разнообразных форм социального отчуждения личности все более ограничивают ее возможности контролировать и управлять жизненными условиями своего существования, прогнозировать тенденции их изменений. Это обусловливает возрастающую зависимость личности от непредсказуемо изменяющейся объективной ситуации, сужает реальную сферу индивидуальной автономности. В таких условиях личность, воспитанная в традициях индивидуализма, самореализуясь и самоутверждаясь, пытается найти иные формы и способы осуществления своего права на автономность и находит его по преимуществу в сфере несущественного и случайного. Отчасти и поэтому (хотя, на наш взгляд, не только поэтому), «новый индивидуализм провозглашает в теории и обещает, но не может обеспечить подлинной и радикальной свободы самоопределения и самоутверждения» [2, с. 121].

Кризисные изменения в содержании идентичности личности и процесса ее идентификации протекают в тесной связи с другим, можно сказать, знаковым для современного общества процессом манипулирования сознанием личности. Непрестанно совершенствуясь в своих технологических и технических возможностях и принимая все боль- 
шие масштабы, он ориентирован прежде всего на внедрение в сознание и подсознание индивида потребительских ценностей и стереотипов поведения, формирование некритичного восприятия социальных реалий. Подавление же критических возможностей мышления личности фактически парализует и ее способность к рефлексии. «Поэтому человек с неразвитой системой социальных, культурных и духовных потребностей (именно таков индивид-потребитель как объект манипулирования - B.П., M.X.) не в состоянии противостоять манипулятивным воздействиям, обещающим удовлетворение потребительских интересов. Происходит это потому, что сильные мотивы, к которым апеллируют создатели пропаганды и рекламы снижают рефлексивные возможности индивида» [7, с.94].

Вследствие сказанного манипулирование сознанием и подсознанием индивида существенно затрудняет и деформирует процесс его идентификации. Навязывание индивиду чуждых ему представлений, ориентаций и ценностей в итоге приводит к подмене его личностного образа «я» и его идентичности в целом. Замещение же в ходе манипулирования подлинных духовных ценностей утилитарно-потребительскими и неспособность манипулируемой личности к саморефлексии закрывают перед ней возможность осознания происшедшей подмены ее идентичности, которая, по сути, принимает форму псевдоидентичности. Череда сменяющих друг друга на протяжении жизни личности «идентичностей» приобретает характер процесса квазиидентификации.

Проблема поиска путей и форм преодоления современного кризиса идентичности личности, на наш взгляд, должна ставиться и обсуждаться в контексте более широкой проблемы - кризиса в целом духовной культуры современного общества. Кризис личностной идентичности является лишь одним, хотя и чрезвычайно важным аспектом названной проблемы, наряду с кризисами духовности, свободы, рациональности и др. Преодоление же кризиса современной духовной культуры вряд ли возможно посредством поиска частных решений терапевтического характера. На наш взгляд, здесь не обойтись без коренной трансформации фундаментальных основ современного общества как буржуазной техногенной цивилизации.

\section{1 Литература}

[1] Барулин В.С. Основы социально-философской антропологии. М.: ИКЦ «Академкнига», 2002. 
[2] Бауман З. Индивидуализированное общество.-М.: Логос, 2002.

[3] Бердлев Н.А. Смысл творчества // Бердяев Н.А. Философия свободы. Смысл творчества. - М.: Изд-во «Правда», 1989.-С. 254580 .

[4] Крымский С.Б. Контуры духовности: новые контексты идентификации // Вопросы философии. - 1992. - № 12. - С. 21-28.

[5] «Лунъ юй» // Древнекитайская философия. Собрание текстов в двух томах. - Т. 1. - М.: Мысль, 1972. - С. 139-174.

[6] Оже $M$. Кризис смысла в современном мире // Философская и социологическая мысль. - 1995. - № 5-6. - С. 130-150.

[7] Пашукова Т.И. Манипуляция сознанием и возможности психологической защиты // Профілактика психологічного насильства і маніпулювання свідомістю та розвиток критичного мислення в молодіжному середовищі / Матеріали Міжнародної науковопрактичної конференції (27-28 травня 2004 року, м. Київ). - К., 2005. - C. 91-99.

[8] Унамуно $M$. Вечная традиция // Философская и социологическая мысль. - 1995. - № 11-12. - С. 112-116.

[9] Фромм Э. Пути из больного общества // Проблема человека в западной философии: Переводы.-М.: Прогресс, 1988.-C.443482.

[10] Хабермас Ю. Понятие индивидуальности // Вопросы философии. -1989 . - № 2. - С. 35-40. 